Article

\title{
Study on Micro Interfacial Charge Motion of Polyethylene Nanocomposite Based on Electrostatic Force Microscope
}

\author{
Bai Han ${ }^{1,2,3, *}$, Jiaxin Chang ${ }^{1,2,3, *}$, Wei Song ${ }^{1,2,3}$, Zhi Sun ${ }^{1,2,3}$, Chuqi Yin ${ }^{1,2,3}$, Penghao Lv $1,2,3$ \\ and Xuan Wang ${ }^{1,2,3}$ \\ 1 Key Laboratory of Engineering Dielectrics and Its Application, Ministry of Education, Harbin University of \\ Science and Technology, Harbin 150080, Heilongjiang, China; songwei791214@163.com (W.S.); \\ sunzhimems@163.com (Z.S.); ChuqiYinhust@163.com (C.Y.); lvpenghao95@163.com (P.L.); \\ wangxuan@hrbust.edu.cn (X.W.) \\ 2 State Key Laboratory Breeding Base of Dielectrics Engineering, Harbin University of Science and Technology, \\ Harbin 150080, Heilongiiang, China \\ 3 College of Electrical \& Electronic Engineer, Harbin University of Science and Technology, Harbin 150080, \\ Heilongjiang, China \\ * Correspondence: bhan@hrbust.edu.cn (B.H.); 18845169304@163.com (J.C.); Tel.: +86-451-8639-1667 (B.H.); \\ +86-188-4516-9304 (J.C.)
}

Received: 13 November 2019; Accepted: 5 December 2019; Published: 9 December 2019

\begin{abstract}
The interface area of nano-dielectric is generally considered to play an important role in improving dielectric properties, especially in suppressing space charge. In order to study the role of interface area on a microscopic scale, the natural charge and injected charge movement and diffusion on the surface of pure LDPE and $\mathrm{SiO}_{2} / \mathrm{LDPE}$ nanocomposite were observed and studied by gradual discharge under electrostatic force microscope (EFM). It was detected that the charge in $\mathrm{SiO}_{2} / \mathrm{LDPE}$ nanocomposite moved towards the interface area and was captured, which indicates that the charge was trapped in the interface area and formed a barrier to the further injection of charge and improving the dielectric performance as a result. Moreover, pulsed electro-acoustic (PEA) short-circuited test after charge injection was carried out, and the change of total charge was calculated. The trend of charge decay in the EFM test is also generally consistent with that in PEA short-circuit test and can be used to verify one another. The results revealed the law of charge movement and verified the interface area can inhibit space charge injection in nano-dielectric at the microscale, which provides an experimental reference for relevant theoretical research.
\end{abstract}

Keywords: electrostatic force microscope (EFM); interface area; space charge; $\mathrm{SiO}_{2} / \mathrm{LDPE}$ nanocomposite

\section{Introduction}

High voltage direct current (HVDC) transmission system has the advantages of large transmission capacity, small loss, good stability, and low cost. The research and development of HVDC cables have become very important with the urgent demand for urban power transmission cables with larger capacity and higher voltage. In this development process, the most critical problem is the insulation strength of polyethylene material and the space charge accumulation under a high electric field [1]. Electric charges are easily injected into the middle of the insulating material under the condition of high electric field, resulting in the accumulation of space charge [2]. The existence of a large amount of space charge will form the distortion of the local electric field, which will lead to such problems as decreasing breakdown voltage, accelerating the growth of electrical tree, water tree, and aging. In order to solve the problem of space charge accumulation of insulating materials under a high electric field, 
the research on nano-dielectric has developed rapidly [3-5]. Many studies have shown that doping with nanoparticles is beneficial to improving the charge distribution of polymers in a high electric field. For example, nano $\mathrm{SiO}_{2}, \mathrm{MgO}, \mathrm{ZnO}$, and other inorganic oxide doping can effectively improve the dielectric properties of composite materials $[1,5,6]$. However, the research on the mechanism of improving dielectric properties of nano-dielectric has not been universally accepted so far. Representative theories are as follows, in order to explain the nano-dielectrics with the excellent electrical properties by doping nanoparticles, Lewis [7] proposed a two-layer model in nano-dielectrics to recognize and exploit the unique qualities of nano-dielectric. Tanaka [8] proposed a multi-core model based on the colloid theory to describe the multifaceted characteristics of polyamide nanocomposites. These theories cannot perfectly explain the various phenomena of nano-dielectric and have no universality. Nevertheless, the importance of the interface area between nanoparticles and polymer matrix is emphasized in both of them. In subsequent studies, most of the researchers believed that the improvement of space charge injection of nano-dielectrics under high electric field mainly depended on the action of interface area formed between nanoparticles and polymer matrix $[9,10]$. The interface area can provide more traps and trap level in nano-dielectrics to capture charge, which cannot be moved easily under high electric field, which will form a blocking electric field and reject the charge further injection, and prevent the distortion of the local electric field [11]. Although this conclusion is generally accepted by many studies, there is a lack of research on the microscopic physical phenomena of the interface, especially the charge injection distribution and movement around the interface area. This is mainly due to the difficulty in observing the structure and charge distribution at the micro-scale of the interface area, especially the law of charge motion is difficult to grasp.

Scanning probe microscope (SPM) is a kind of high-resolution microscope with multiple scanning modes, and its electric force microscope (EFM) mode is an effective method to observe the distribution of electric field (charge) at micro-scale [12]. By using various scanning modes of SPM, including EFM mode, some researchers studied various characteristics and rules of dielectric parameters of nanoparticles in nano-dielectric, including local dielectric spectroscopy, charging response and polarization properties. Labardi used EFM to detect the local dielectric constant around nanoparticles in nano dielectric [13]. Borgani applied charge and discharge processing in $\mathrm{LDPE} / \mathrm{Al}_{2} \mathrm{O}_{3}$ and characterized the trap energy level on $\mathrm{Al}_{2} \mathrm{O}_{3}$ nanoparticles by EFM [14]. Peng used EFM to measure the dielectric constant of the interface area around nano- $\mathrm{TiO}_{2}$ in $\mathrm{LDPE} / \mathrm{TiO}_{2}[15]$ and the polarization around nanoparticles in $\mathrm{P}(\mathrm{VDF}-\mathrm{TrFE}) / \mathrm{BT}$ [16]. These results have provided important experimental data for interface research in nano-dielectric. However, most of these studies are carried out under the condition of steady state of charge in nano-dielectrics and little attention is paid to the movement of charge around nanoparticles in nano-dielectrics.

In the study of nano-dielectric, the charge distribution on the micro-scale and the change rule with time can reveal and characterize the charge distribution characteristics in nano-dielectric, especially near the interface area observed by EFM, which provides strong support for the theory of interface area. In this paper, the charge distribution and motion characteristics in LDPE and $\mathrm{SiO}_{2} / \mathrm{LDPE}$ nanocomposite are studied under suitable discharge treatment and observation time. In this paper, LDPE is chosen as a matrix material because it is a representative insulating material in HVDC cables and its structure is relatively simple [14]. The natural discharge process and the charge distribution and change process after charge injection of $\mathrm{LDPE}$ and $\mathrm{SiO}_{2} / \mathrm{LDPE}$ nanocomposite especially the change of charge distribution around nanoparticles were studied continuously under EFM observation. The change law of the charge in the nano-dielectric including the charge around the nanoparticle can reflect the trap characteristics inside the material, so as to verify the important role of the interface area after the nano- $\mathrm{SiO}_{2}$ doping. Moreover, to verify the EFM experiment results, pulsed electro-acoustic (PEA) method under short-circuited discharge is used to determine whether this charge movement law occurs locally or globally in the nanocomposite. The consistency of EFM and PEA results can prove the reliability of EFM micro-area experimental results. 


\section{Experimental}

\subsection{Materials Preparation}

LDPE produced by Daqing petrochemical company (Daqing, China) and model M-5 gas phase nano- $\mathrm{SiO}_{2}$ produced by Cabot company (Boston, Massachusetts, US) were used in this experiment. The diameter of nano-SiO 2 is $100 \mathrm{~nm}$. The LDPE was melted with Hapro RM-A200 rheometer (Harbin, China) at $130{ }^{\circ} \mathrm{C}$, and then the dispersion of $\mathrm{SiO}_{2} /$ alcohol was then dripped into it. The doping content of $\mathrm{SiO}_{2}$ is $0.5 \mathrm{wt} \%$. The rotor speed was set to $60 \mathrm{r} / \mathrm{min}$ and the material was continuously stirred until the torque of the rheometer is constant to evenly disperse the $\mathrm{SiO}_{2}$ in LDPE. A flat vulcanizing machine was adopted to form the samples into films. In particular, the EFM (Bruker Multimode 8, Billerica, MA, USA) test sample was formed at a thickness of $50 \mu \mathrm{m}$ with a mica film with a super flat surface. The advantage of using mica is using its super flat surface to make the surface of samples as smooth as possible. It can expose the part of the doped nanoparticles and help to eliminate the influence of surface fluctuation on charge injection and charge measurement. The PEA test samples were coated with $25 \mathrm{~mm}$ diameter aluminum electrodes on both sides and placed in a $50{ }^{\circ} \mathrm{C}$ oven for $24 \mathrm{~h}$ under short-circuit to eliminate the internal charge.

\subsection{EFM Measurement}

EFM is based on the tapping mode and lift mode of SPM [17], its working principle is shown in Figure 1. First, tapping mode was used to scan the surface morphology of the sample, as shown in Figure 1a. In order to prevent the sample surface from being damaged by the tip, the probe vibrated on the sample surface and touched the sample surface lightly during the scanning. Next, the reflected signal of the laser applied on the probe collected by a photodetector was recorded to detect the displacement of the probe, and then, reflect the surface morphology of the sample. After tapping mode was used to scan a line of the sample surface, lift mode was used to scan the same line again, as shown in Figure 1b. In lift mode, the probe was not in contact with the sample surface but was driven to vibrate at a fixed height (lift height) above the sample surface [18]. At this point, the probe followed stored surface morphology at the lift height above the sample while responding to electric influences between the tip and sample surface on the second scan. A photodetector was also used to collect the signal and record the motion of the probe, as well as record and analyze the phase of the probe vibration waveform to present it on the phase diagram. Therefore, the phase diagram can reflect the electric field force distribution.

(a)

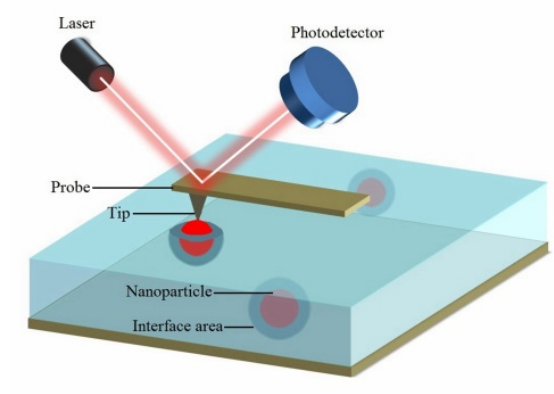

(b)

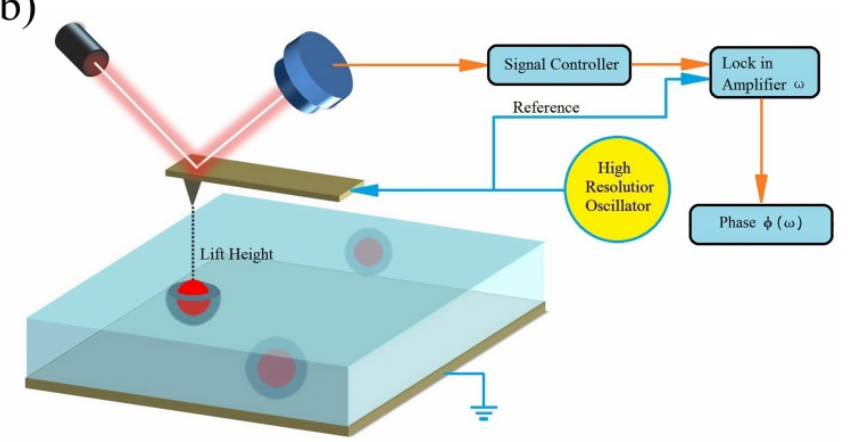

Figure 1. Working principle of electric force microscope (EFM), (a) tapping mode in EFM, (b) lift mode in EFM.

After the samples were pressed into films, there was a large amount of surface charges on the surfaces of pure LDPE and $\mathrm{SiO}_{2} / \mathrm{LDPE}$ nanocomposite, which may have been generated during high-temperature processing, or generated by the friction charge between mica and the surface of the samples [19]. These surface charges remained on the surface and were difficult to dissipate, which 
exerted a strong electric field force on the probe during the EFM test, making it impossible to test surface charge. This was also the difficulty of surface electric field force test for LDPE all along.

In order to observe the discharge process of the natural charge on the surface of the sample, the method of gradual discharge of surface charge was used to reduce the influence of a large amount of surface charge in the test. The process was to stick the back of the sample on the metal sample table by silver conductive tape making the side of the EFM test to be measured facing up. Then, a clean flat electrode was placed on the sample surface and connected with the metal sample table by wire and grounded at the same time to release the surface charge. The sample was discharged at $50{ }^{\circ} \mathrm{C}$ until $24 \mathrm{~h}$, the phase of the surface could be detected. Then, the surface of the sample was scanned by EFM mode, and the morphology and phase diagram were obtained. In the EFM testing process, in order to avoid the influence of van der Waals force and to better detect the change of electrostatic force, the lift height of the interleave was set as $20 \mathrm{~nm}$ [20]. After scanning, the sample was discharged again as mentioned above until discharge time reached 48 and $72 \mathrm{~h}$. Under the condition of retaining the original parameters, the in-situ area of the sample was found and scanned again in EFM mode. By using the software of SPM (Bruker Multimode 8, Billerica, MA, USA), phase data of the same line on the sample were extracted after different short-circuit times.

After the experiments mentioned above, the SPM probe was used to inject charge into the surface of the sample, and then the change of surface charge was observed by EFM. The experimental processes were as follows: First, the surface of the sample was cleaned with pure water, and the surface charge was fully released without damaging the surface morphology of the sample. Then, the sample was placed in an oven at $50{ }^{\circ} \mathrm{C}$ to dry for $1 \mathrm{~h}$, and the sample was stuck on the surface of the sample table with a conductive tape. SPM contact mode was then adopted to contact the sample with the tip and inject charge. The tip bias of $-12 \mathrm{~V}$ and injection range of $500 \mathrm{~nm} \times 500 \mathrm{~nm}$ were adopted. Finally, EFM mode was used to perform in-situ characterization of the sample surface with the same parameters as before and scanning was repeated for $3 \mathrm{~h}$ continuously to observe the movement of charge. The EFM scanning observation range was set to $5 \mu \mathrm{m} \times 5 \mu \mathrm{m}$ and probe lift height was set to $20 \mathrm{~nm}$.

\subsection{Space Charge Measurement}

In order to provide a macroscopic data reference for the charge variation in the sample, the charge variations of the whole samples during short-circuit conditions were measured. The space charge measurement of the specimen was performed in a PEA system. The PEA method is a method of measuring the charge distribution in the direction of material thickness. A high voltage source was used to apply a polarization voltage to the upper side of the sample and a pulse source was applied to the sample to generate electrical pulses regularly. According to the pulsed electro-mechanical stress effect, when the electrical pulse was applied, the charge in the sample generated a pressure wave and conduct to the lower electrode [21]. Since the propagation of the electrical pulse is much faster than the pressure wave, the pressure wave of the whole sample is considered to be generated simultaneously. According to the distance to the lower electrode, the pressure wave at each position propagates to the lower electrode in order. A PVDF piezoelectric sensor was placed under the lower electrode to convert the pressure signal into an electrical signal. By analyzing the process of pressure signal propagation and superposition, the obtained electrical signal waveform was processed to obtain the vertical distribution of charge in the sample. When the voltage was applied for a certain period of time, the high voltage source could be removed so that both ends of the sample were grounded. The space charge distribution at different short-circuit times can be detected. In the PEA test, an electric field with the electric field intensity of $50 \mathrm{kV} / \mathrm{mm}$ was applied and kept for $30 \mathrm{~min}$ so as to make the charge injected. After that, the sample was short-circuited and the change rule of charge distribution with the increase of time was recorded. Then, the space charge distribution of a short circuit was used to calculate the residual charge inside the sample at $10 \mathrm{~s}, 15,30 \mathrm{~min}, 1,2,3,24,48,72 \mathrm{~h}$ after a short circuit. Although the PEA method was used to measure the charge distribution and charge amount 
of the whole sample, the charge near the surface of the sample occupied most of it $[5,8]$. Meanwhile, the charge distribution and total amount in the sample corresponded to the charge distribution and amount near the sample surface [22]. Therefore, the change rule of residual charge in the sample by PEA test can provide reference and correspondence for surface charge variation in the EFM test.

\section{Results and Discussion}

The information of the EFM phase is very complicated. While the lift height is $z$, and the detected location is unchanged, according to the widely accepted mathematical model [23], the equation can be drawn as Equation (1):

$$
\Delta \varphi \approx \frac{Q}{k} \frac{\partial F(z)}{\partial z}=\frac{Q}{k} \frac{q_{s}}{4 \pi \varepsilon_{0} z^{3}}\left(q_{t}+2 C V\right)
$$

where $\Delta \varphi$ is the phase, $Q$ is the quality factor of the tip, $k$ is the elasticity modulus of the tip, $q_{s}$ is the amount of charge on the sample surface, $q_{t}$ is the amount of charge on the tip. And $V=V_{c}+V_{\text {tip }}, V_{c}$ is the work function difference between the tip and the sample surface, $V_{\text {tip }}$ is the Tip Bias. When the same area is scanned repeatedly, $V_{c}$ does not change. In other EFM experiments, the influence of $V_{c}$ cannot be completely eliminated. Because $q_{t}$ depends on $q_{s}$, only if $q_{s}$ changes, $\Delta \varphi$ will change. It can be inferred that the different measured phase values $\Delta \varphi$ in the same region must be caused by the change of $q_{s}$. It should be pointed out that $\Delta \varphi$ is not proportional to $q_{s}$, but proportional to $q_{s}^{2}$ [24]. It can be considered that the phase information in EFM mode can be used to represent the information of the local charge amount.

Surface morphology of pure LDPE is shown in Figure 2a. The phase diagrams of discharge for 24, 48 and $72 \mathrm{~h}$ are shown in Figure $2 \mathrm{~b}-\mathrm{d}$. Phase data at different times were selected from a horizontal line (white line) in the middle of the figure and were shown in Figure 2e. As it is shown in Figure 2a, pure LDPE surface morphology is relatively flat, with no obvious fluctuation. It can be seen from the surface morphology that the structure of polyethylene crystalline lamellae or spherulites (in the light color area) is disorganized in the matrix and there is no obvious rule [25,26]. After discharge for $24 \mathrm{~h}$, the surface charge of LDPE was not significantly concentrated and evenly distributed. After $48 \mathrm{~h}$ of discharge, the surface charge of LDPE dissipated obviously, and the residual charge was more difficult to detect. After $72 \mathrm{~h}$ of discharge, the surface charge could not be detected, and the phase signals were all noises. It indicates that the surface charge of LDPE had completely dissipated. The charge line distribution rule shown in Figure 2e also fully proves these phenomena in pure LDPE. When the discharge time reaches $24 \mathrm{~h}$, the surface charge distribution curve has some fluctuates, but the amplitude is small. There is no obvious correspondence between the surface charge distribution curve and the morphology. When the discharge time reaches 48 and $72 \mathrm{~h}$, there is only a slight difference between the phase signal and noise, which means there is no obvious charge distribution on the surface.

Similarly, the surface morphology of $\mathrm{SiO}_{2} / \mathrm{LDPE}$ is shown in Figure 3a, and the phase diagrams of discharge for 24, 48, and $72 \mathrm{~h}$ are shown in Figure 3b-d. As it is shown in Figure 3a, $\mathrm{SiO}_{2} / \mathrm{LDPE}$ has almost the same surface structure as LDPE, its surface is flat. However, unlike LDPE, an exposed nano- $\mathrm{SiO}_{2}$ particle (in red circle) was detected at the lower-left corner of the diagram. It can be observed that the nanoparticle's diameter is about $150 \mathrm{~nm}$. In order to visually reflect the line distribution and relative amount of charge, a straight line (white line) was selected to cross the nanoparticles and the interface area. Phase data extracted from the line are shown in Figure 3e. After $24 \mathrm{~h}$ discharge, charges were concentrated in several areas, including the area around the nanoparticles. Meanwhile, concentrated charges were also detected in the region out of the exposed nanoparticle. It might be the charge at the interface area around the unexposed subsurface nanoparticles [27]. Regarding the concentrated charge marked in a blue circle, each charge bright spot represents a nanoparticle which is not exposed, and the distribution and the size of these bright spots indicate that the nanoparticles are evenly distributed in the matrix. After $48 \mathrm{~h}$ discharge, as it is shown in Figure $3 \mathrm{c}$, it could be found that the charge of the subsurface and the exposed nanoparticles decreased. After $72 \mathrm{~h}$, the phase around the subsurface nanoparticle disappeared. However, the phase of nanoparticles in Figure $3 e$ can still be 
distinguished from the matrix phase, which may be due to the difference in work function between nanoparticles and the LDPE matrix [23]. Compared with the pure LDPE, the phase range of $\mathrm{SiO}_{2} / \mathrm{LDPE}$ in Figure $3 e$ is significantly larger, and its peak value even ten times larger than that of the LDPE.
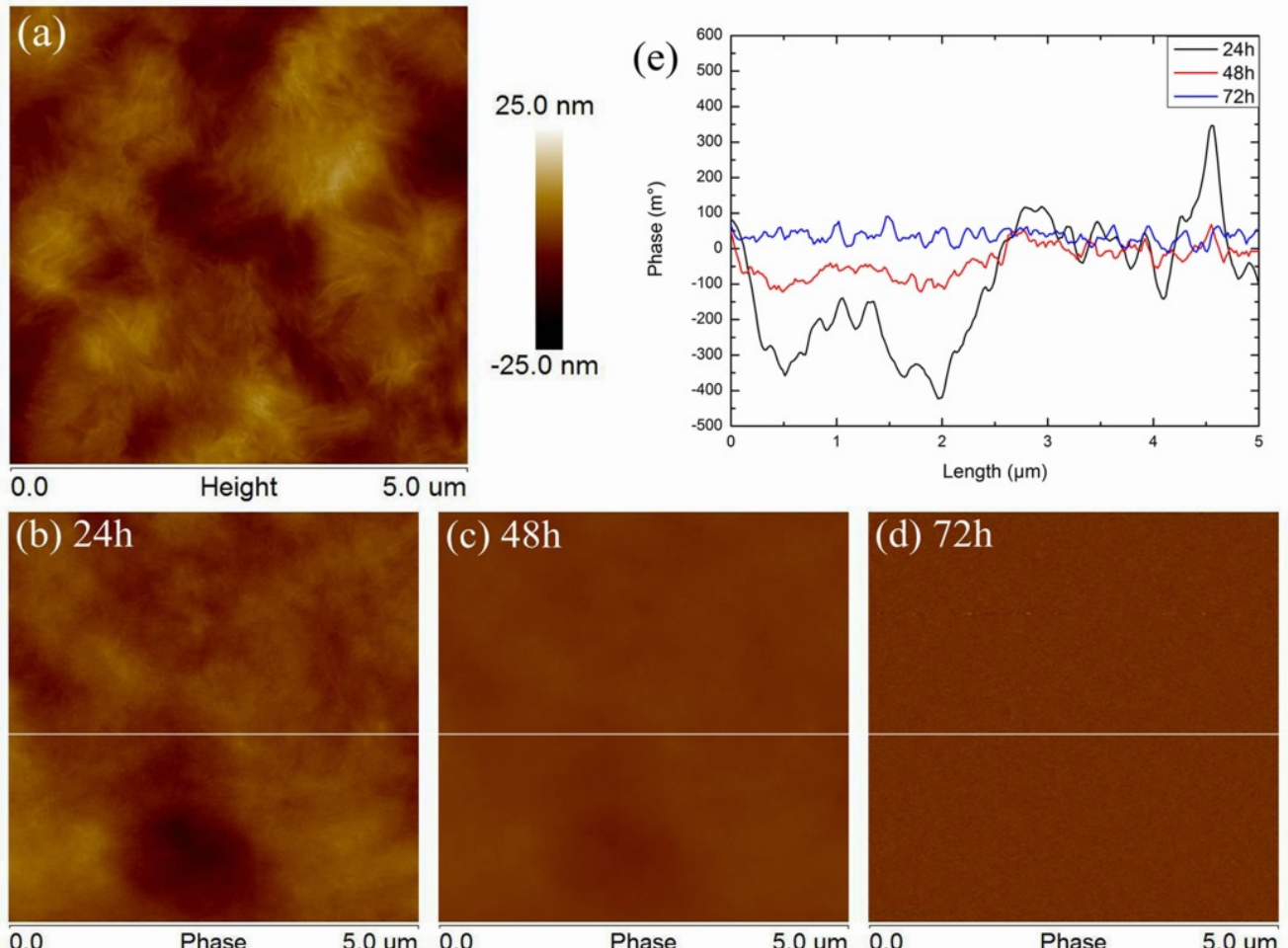

Figure 2. LDPE surface morphology and phase, (a) surface morphology, phase after discharge for $24 \mathrm{~h}$ (b), $48 \mathrm{~h}(\mathbf{c}), 72 \mathrm{~h}(\mathrm{~d})$, and phase data (e) detected from white line.
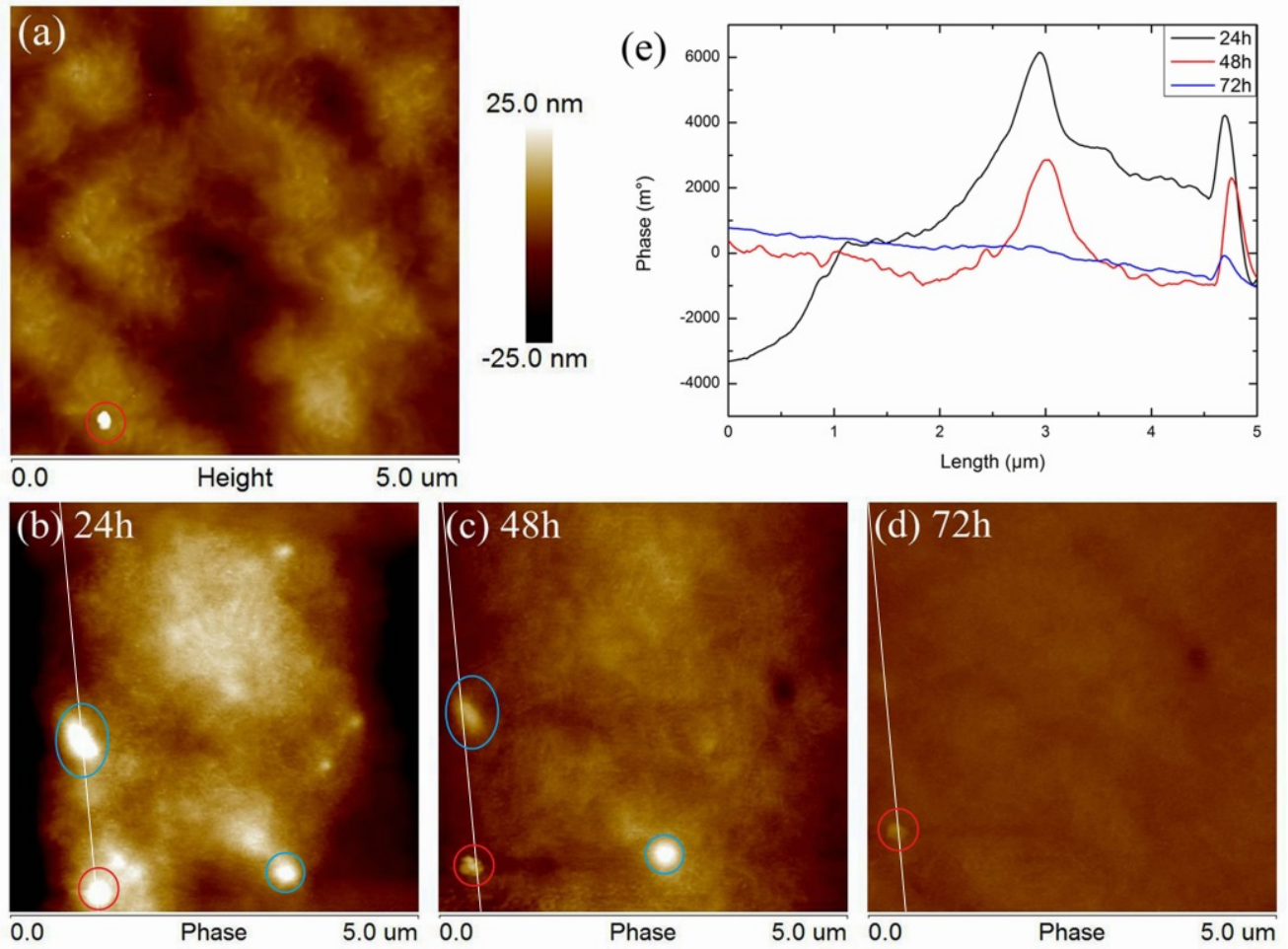

Figure 3. $\mathrm{SiO}_{2} / \mathrm{LDPE}$ nanocomposite surface morphology and phase, (a) surface morphology, phase after discharge for $24 \mathrm{~h} \mathrm{(b),} 48 \mathrm{~h}(\mathbf{c}), 72 \mathrm{~h}(\mathbf{d})$, and phase data (e) detected from white line. 
The above experimental results show that, compared with LDPE, the surface of $\mathrm{SiO}_{2} / \mathrm{LDPE}$ is more likely to accumulate charge, especially in the interface area around the nanoparticles. Meanwhile, the charge dissipation rate of $\mathrm{SiO}_{2} / \mathrm{LDPE}$ is significantly slower than that of LDPE, which indicates that the interface area generated by the doping of nano- $\mathrm{SiO}_{2}$ particles is more likely to capture electrons. It can be considered that there are a lot of traps in the interface area induced by nano- $\mathrm{SiO}_{2}$ particles doping, which makes it difficult for the trapped electrons to escape, forming the accumulated charge and making it difficult to dissipate [28].

After the sample was fully discharged, the charge was injected into the surface of the sample by the method mentioned above, and then, the surface of the sample was continuously scanned by EFM mode. After charge injection, the surface morphology of LDPE is shown in Figure 4a, the trace produced by the contact between the probe and the surface of the sample during the charge injection can be observed. Phase figures of 10, 20, 30, and $180 \mathrm{~min}$ after charge injection are shown in Figure 4b-e. The same as the previous method, a straight line was selected through the charge injection region, the data were extracted on it, and Figure $4 \mathrm{f}$ was drawn. Ten min after injection, the charge was found in the charge injection region and its surrounding region. When discharge time reached $20 \mathrm{~min}$, the phase of the injection region decayed to $1 / 3$ of that at $10 \mathrm{~min}$. The charge around the injection region decreased significantly, and it spread isotropically. When the discharge time reached $30 \mathrm{~min}$, the phase data of the injected area could not be distinguished from the surrounding area, and almost no charge residue could be seen. Furthermore, after the discharge time reached $180 \mathrm{~min}$, the phase of the charge injection area was completely consistent with the surrounding area. The surface charge of LDPE dissipated very quickly after the injection, and it was difficult to stay on the surface. This trend of charge variation in LDPE could also be clearly observed in Figure 4 f.
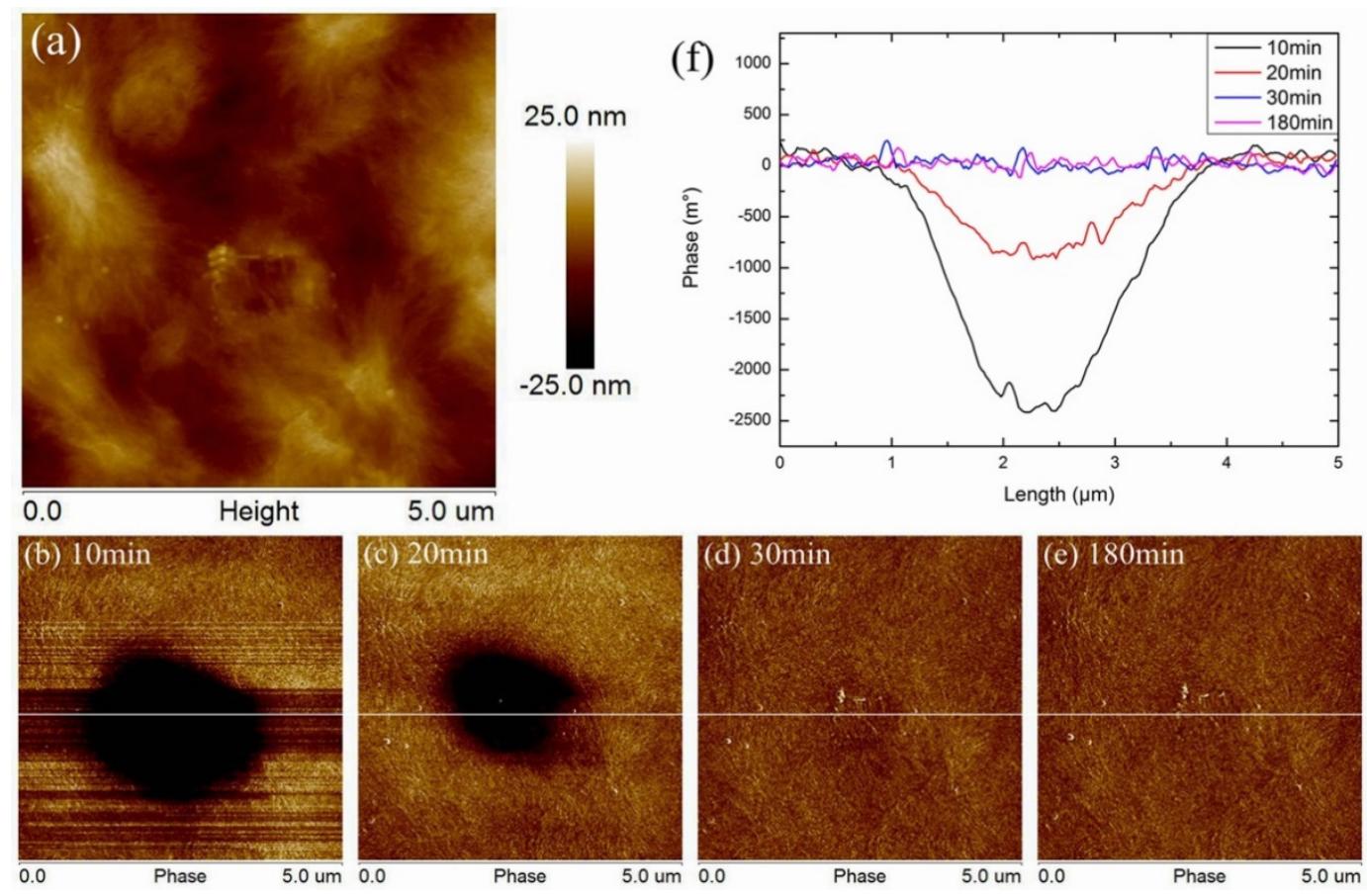

Figure 4. Morphology and phase of LDPE after charge injection, (a) surface morphology, phase after charge injection $10 \mathrm{~min}(\mathbf{b}), 20 \mathrm{~min}(\mathbf{c}), 30 \mathrm{~min}(\mathbf{d}), 180 \mathrm{~min}(\mathbf{e})$, and phase data (f) detected from white line.

Figure $5 \mathrm{a}$ is the surface morphology of $\mathrm{SiO}_{2} / \mathrm{LDPE}$ after charge injection. It can be seen from Figure $5 \mathrm{a}$, different from LDPE, there is an exposed nanoparticle on the surface of $\mathrm{SiO}_{2} / \mathrm{LDPE}$ shown in the red circle. The phases of 10, 30, 60, and 180 min after charge injection are shown in Figure 5b-e. A straight line was connected between the nanoparticles and the charge injection point, the charge 
data were extracted on this line, and a graph at different discharge times was drawn, as shown in Figure $5 f$. Ten min after charge injection, the maximum phase of $\mathrm{SiO}_{2} / \mathrm{LDPE}$ surface was only about $1 / 4$ of that of LDPE. At the same time, the phase of nanoparticles was slightly higher than that of the matrix but with little difference. After $30 \mathrm{~min}$, the surface phase decayed slightly, while at the same time, the surface charge of LDPE basically decayed to undetectable. Obviously, the surface charge decay rate of $\mathrm{SiO}_{2} / \mathrm{LDPE}$ was much slower. When the discharge time reached $60 \mathrm{~min}$, the phase peak value of the injection region had no significant attenuation in $\mathrm{SiO}_{2} / \mathrm{LDPE}$. However, in the area around the nanoparticles, charge began to accumulate even more obviously than the injection region, as shown in Figure 5d. Charge accumulation in the non-injected region indicates that the interface area formed around the nanoparticles has a significant charge trapping effect. It is worth pointing out that the interface area around the nanoparticle that accumulates charge is significantly larger than the size of the nanoparticle itself, suggesting that the range of the interface area is much larger than other theories had predicted. Hundred eighty min after charge injection, both the phase in the charge injection area and in the interface area around the nanoparticle were reduced slightly and could still be clearly distinguished from the matrix. It means that, as time goes on, the charge dissipates slowly. At this time, in LDPE, the existence of an injected charge could not be detected at all.
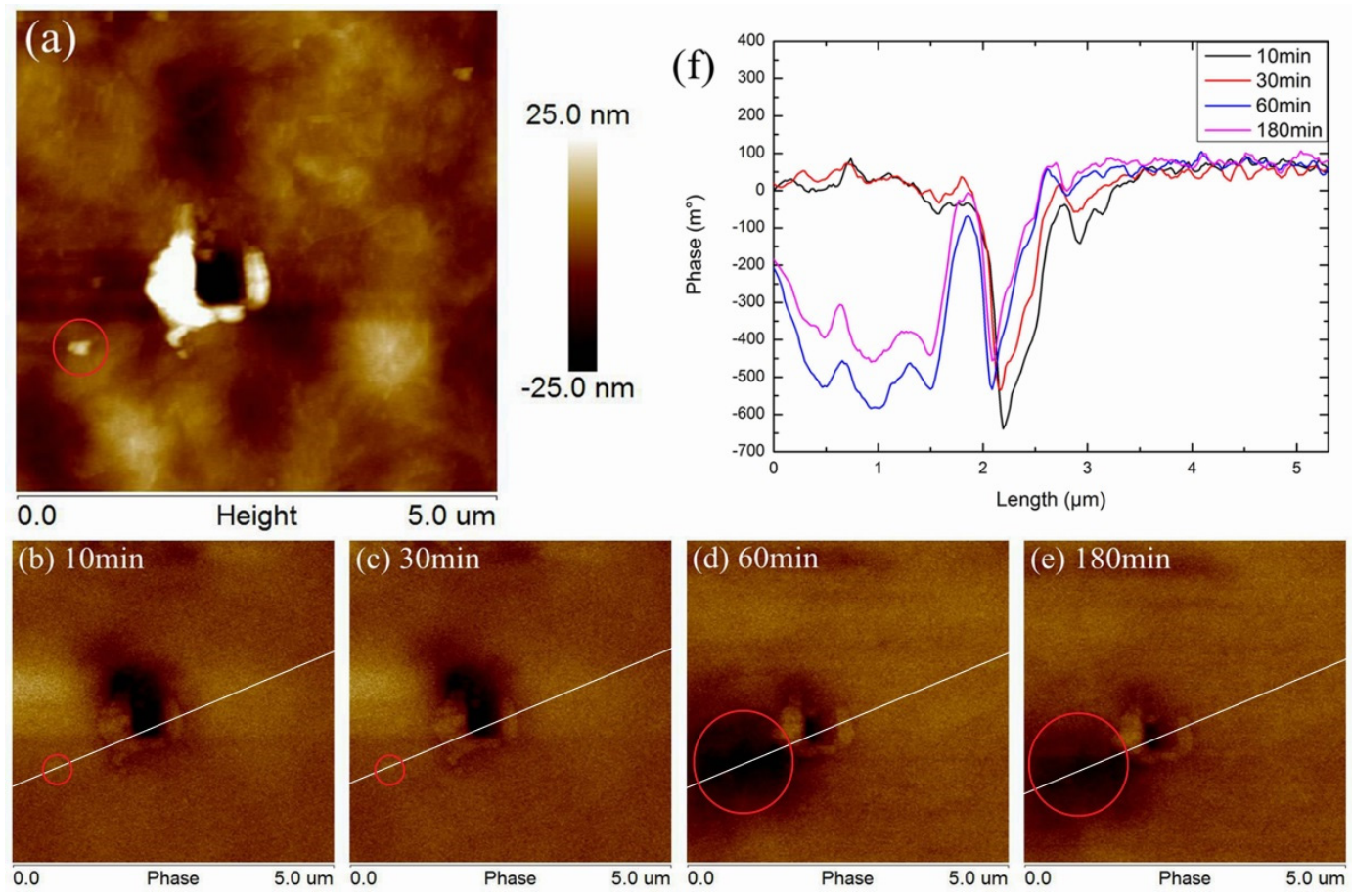

Figure 5. Morphology and phase of $\mathrm{SiO}_{2}$ /LDPE after charge injection, (a) surface morphology, phase after charge injection $10 \mathrm{~min}(\mathbf{b}), 30 \mathrm{~min}(\mathbf{c}), 60 \mathrm{~min}(\mathbf{d}), 180 \mathrm{~min}(\mathbf{e})$, and phase data (f) detected from white line.

The above phenomena indicate that the total amount of charge injected into $\mathrm{SiO}_{2} / \mathrm{LDPE}$ nanocomposites is smaller than pure LDPE, but the charge dissipates faster in pure LDPE. Moreover, the charge in $\mathrm{SiO}_{2} / \mathrm{LDPE}$ is more likely to move and accumulate in the interface area around $\mathrm{SiO}_{2}$ nanoparticles and dissipate more slowly. This suggests that the interfacial region around the $\mathrm{SiO}_{2}$ nanoparticles in the composite introduces more traps in the interface area due to the doping of nano- $\mathrm{SiO}_{2}$. These traps are more likely to trap free-moving electrons and limit their dissipation. It is the presence of these trapped charges that increases the surface barrier of $\mathrm{SiO}_{2} / \mathrm{LDPE}$ and inhibits the charge injection under high electric field, in this way, dielectric properties of $\mathrm{SiO}_{2} / \mathrm{LDPE}$ nanocomposite improved [29]. 
In order to obtain the magnitude of the local electric field of the charge injected by SPM contact mode, the physical field simulation of charge injection was conducted by COMSOL Multiphysics and the simulation results are shown in Figure 6. In the simulation, the radius of the tip was set as $30 \mathrm{~nm}$, side angle of the tip was set as $22.5^{\circ}$, the voltage between the probe and sample is set as $-12 \mathrm{~V}$. The dielectric constant of the sample is set as 2.3 , and the thickness of the sample was $50 \mu \mathrm{m}$. These parameters were derived from the EFM test used in the above experiments. Without considering the effect of work function, when the insertion depth of the probe was $18.5 \mathrm{~nm}$, it can be concluded that the maximum electric field intensity of the tip can reach $84.75 \mathrm{kV} / \mathrm{mm}$, the average electric field intensity of $100 \mathrm{~nm}$ around the tip is $34.13 \mathrm{kV} / \mathrm{mm}$. This electric field intensity is generally consistent with the electric field intensity of space charge distribution under a high electric field test by means of PEA. The space charge distribution characteristics obtained in the discharge of PEA method can be used to calculate the variation of charge density in a short-circuit. Although there is a certain difference between the two experiments, according to the electric field intensity results obtained from the electric field simulation, the electric field intensity is basically at the same value. Moreover, the conductive probe has been in contact with the sample during the EFM test, which can be considered as similar to the experimental conditions of PEA discharge in microscale.

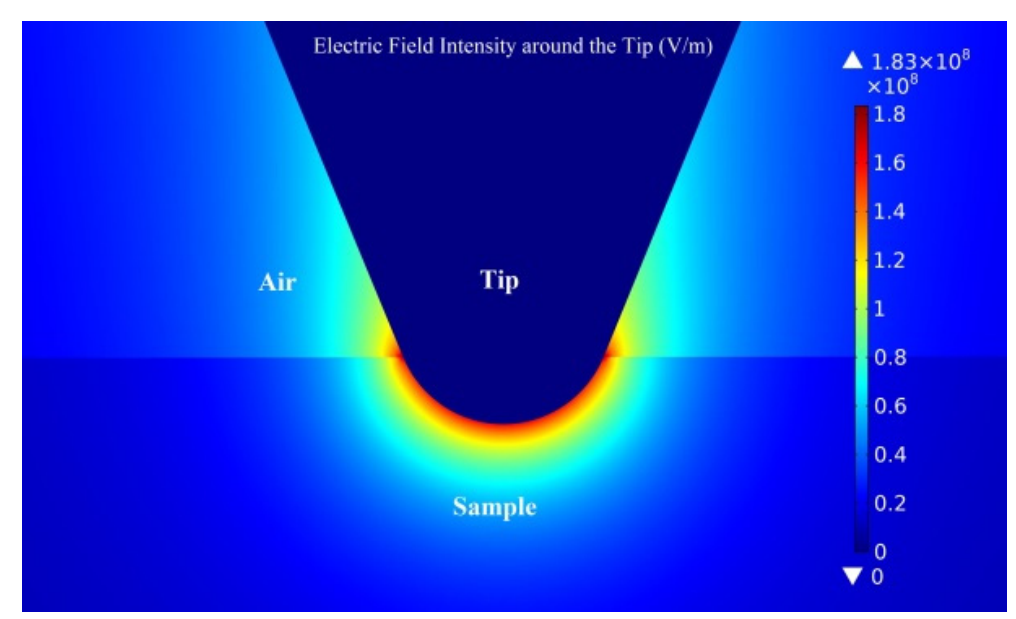

Figure 6. Simulation of the electric field around the tip when charge injecting.

The average charge density of samples measured by the PEA method is calculated by Equation (2) [30]:

$$
Q(t ; E)=\frac{1}{x_{0}-x_{1}} \int_{x_{0}}^{x_{1}}\left|Q_{p}(x ; t ; E)\right| \mathrm{d} x
$$

where $Q_{p}(x ; t ; E)$ is the space charge density when time is $t$, field strength is $E$ and the positon is $x$. Because of different polarity, here taking the absolute value. $x_{0}, x_{1}$ is the location of the cathode and anode, respectively. $t$ is the short circuit time after the polarization electric field is removed and $E$ is the polarization electric field. The average charge volume density of the sample at different times is shown in Figure 7. It can be found that the internal charge density (total charge) of $\mathrm{SiO}_{2} / \mathrm{LDPE}$ is half of that of LDPE at the first $10 \mathrm{~s}$ after a short circuit. With the increasing of short circuit time, the charge and its density in pure LDPE decreased rapidly, while the charge in $\mathrm{SiO}_{2} / \mathrm{LDPE}$ dissipated slower. As the discharge time continually increased, the charge density in $\mathrm{SiO}_{2} / \mathrm{LDPE}$ was gradually higher than that in pure LDPE. In PEA short-circuit test, the doping of $\mathrm{SiO}_{2}$ particles in $\mathrm{SiO}_{2} / \mathrm{LDPE}$ nanocomposites introduced a large number of traps and captured electrons under the action of the electric field, so that a large amount of homopolar charges accumulated near the electrode. These charges formed a high potential barrier near the electrode, making it difficult to inject the charge further [31]. Although pure LDPE has a higher initial charge density, its charge dissipation rate is faster than that of $\mathrm{SiO}_{2} / \mathrm{LDPE}$ nanocomposite. After discharge for about $30 \mathrm{~min}$, the amount of residual 
charge in $\mathrm{SiO}_{2} / \mathrm{LDPE}$ was more than that of pure LDPE. During the discharge lasting for three days, the charge amount in $\mathrm{SiO}_{2} / \mathrm{LDPE}$ was always higher than that in pure LDPE. The phenomenon that the space charge dissipation of $\mathrm{SiO}_{2} / \mathrm{LDPE}$ is slower than that of pure LDPE is basically consistent with the result observed in EFM. Therefore, there is a certain similarity between EFM charge dissipate test and the PEA short circuit test, which can be used for their mutual verification.

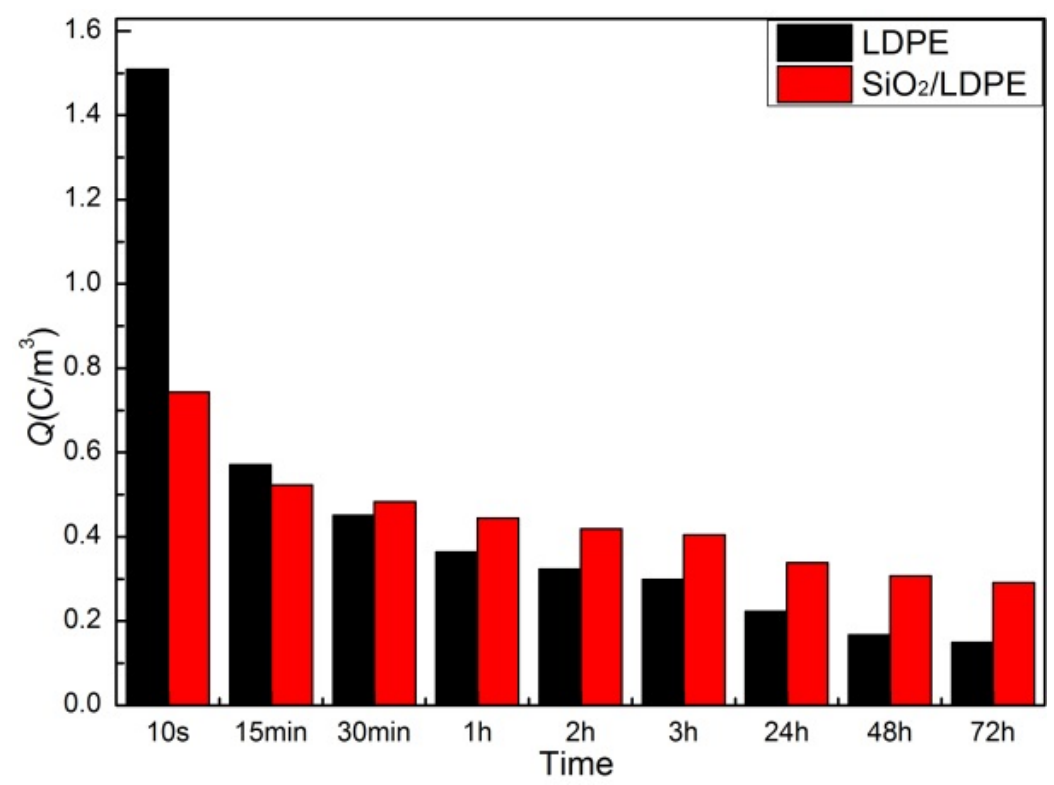

Figure 7. Average charge density of LDPE and $\mathrm{SiO}_{2} / \mathrm{LDPE}$ in short-circuit by PEA method.

\section{Conclusions}

In summary, this paper adopts the method of gradual surface charge discharge and observes the change rule of naturally existing charge dissipation in pure LDPE and $\mathrm{SiO}_{2} / \mathrm{LDPE}$ nanocomposite by EFM. In addition, charge is injected into the same sample and the change process of charge is observed. It is found that no matter the dissipation of natural charge or injected charge, the dissipation process of charge in $\mathrm{SiO}_{2} / \mathrm{LDPE}$ nanocomposite is significantly slower than that of pure LDPE, and charge in $\mathrm{SiO}_{2} / \mathrm{LDPE}$ was mainly concentrated around nanoparticles, that is, gathered near the interface area. Moreover, the short-circuit discharge test through PEA also proves this trend on the macro scale. This proves that the interface area plays an important role on the scale of microscopic observation, indicating that there are a lot of traps in the interface area. The movable charge is trapped in a high electric field and the trapped charge makes it more difficult to inject charge into the dielectric, thus improving the insulation performance of nano-dielectric. The results revealed the law of charge movement and verified the effect of interface area on the inhibition of space charge injection in nano-dielectric at the micro-scale, which provides an experimental basis for relevant theoretical research.

Author Contributions: Conceptualization, B.H. and J.C.; methodology, J.C., and C.Y. software, J.C. and P.L.; validation, B.H. and X.W.; formal analysis, B.H., Z.S. and J.C.; resources, B.H. and W.S.; writing-original draft preparation, J.C.; writing-review and editing, B.H.

Funding: This research was funded by the University Nursing Program for Young Scholars with Creative Talents in Heilongjiang Province (Grant No. UNPYSCT-2016161) and National Natural Science Foundation of China (Grant No. 51607048 and No. 51337002).

Conflicts of Interest: The authors declare no conflict of interest. 


\section{References}

1. Pourrahimi, A.M.; Hoang, A.; Liu, D.; Pallon, L.K.; Gubanski, S.; Olsson, R.T.; Gedde, U.W.; Hedenqvist, M.S. Highly efficient interfaces in nanocomposites based on polyethylene and $\mathrm{ZnO}$ nano/hierarchical particles: A novel approach toward ultralow electrical conductivity insulations. Adv. Mater. 2016, 28, 8651. [CrossRef] [PubMed]

2. Pallon, L.K.H.; Hoang, A.; Pourrahimi, A.M.; Hedenqvist, M.S.; Nilsson, F.; Gubanski, G.U.W.; Olsson, R.T.; Mater, J. The impact of $\mathrm{MgO}$ nanoparticle interface in ultra-insulating polyethylene nanocomposites for high voltage DC cables. Chem. A 2016, 4, 8590. [CrossRef]

3. Nelson, J.K.; Hu, Y. Nanocomposite dielectrics-Properties and implications. J. Phys. D Appl. Phys. 2005, 38, 213-222. [CrossRef]

4. Plesa, I.; Notingher, P.V.; Stancu, C.; Wiesbrock, F.; Schlogl, S. Polyethylene Nanocomposites for Power Cable Insulations. Polymers 2018, 11, 24. [CrossRef] [PubMed]

5. Takada, T.; Hayase, Y.; Tanaka, Y. Space charge trapping in electrical potential well caused by permanent and induced dipoles for LDPE/MgO nanocomposite. IEEE Trans. Dielectr. Electr. Insul. 2008, 15, 152-160. [CrossRef]

6. Lv, Z.; Wang, X.; Wu, K.; Cheng, Y.; Dissado, L.A. Dependence of charge accumulation on sample thickness in nano-SiO 2 doped LDPE. IEEE Trans. Dielectr. Electr. Insul. 2013, 20, 6451375.

7. Lewis, T.J. Interfaces are the dominant feature of dielectrics at the nanometric level. IEEE Trans. Dielectr. Electr. Insul. 2004, 11, 739-753. [CrossRef]

8. Tanaka, T.; Kozako, M.; Fuse, N.; Ohki, Y. Proposal of a multi-core model for polymer nanocomposite dielectrics. IEEE Trans. Dielectr. Electr. Insul. 2005, 12, 669-681. [CrossRef]

9. Ali, F.; Ugurlu, B.; Kawamura, A. Polymer nanocomposite dielectrics-The role of the interface. IEEE Trans. Dielectr. Electr. Insul. 2005, 12, 1273.

10. Smith, R.; Liang, C.; Landry, M.; Nelson, J.; Schadler, L. The mechanisms leading to the useful electrical properties of polymer nanodielectrics. IEEE Trans. Dielectr. Electr. Insul. 2008, 15, 187-196. [CrossRef]

11. Zhou, Y.; Hu, J.; Dang, B.; He, J. Titanium oxide nanoparticle increases shallow traps to suppress space charge accumulation in polypropylene dielectrics. RSC Adv. 2016, 6, 48720-48727. [CrossRef]

12. GarcíA, R.; Rubén, P. Dynamic atomic force microscopy methods. Surf. Sci. Rep. 2002, 47, 197-301. [CrossRef]

13. Labardi, M.; Prevosto, D.; Nguyen, K.H.; Capaccioli, S.; Lucchesi, M.; Rolla, P. Local dielectric spectroscopy of nanocomposite materials interfaces. J. Vac. Sci. Technol. B. 2010, 28, C4D11. [CrossRef]

14. Borgani, R.; Pallon, L.K.H.; Hedenqvist, M.S.; Gedde, U.W.; Haviland, D.B. Local charge injection and extraction on surface-modified $\mathrm{Al}_{2} \mathrm{O}_{3}$ nanoparticles in LDPE. Nano Lett. 2016, 16, 5934. [CrossRef]

15. Peng, S.; Zeng, Q.; Yang, X.; Hu, J.; Qiu, X.; He, J. Local dielectric property detection of the interface between nanoparticle and polymer in nanocomposite dielectrics. Sci. Rep. 2016, 6, 38978. [CrossRef]

16. Peng, S.; Yang, X.; Yang, Y.; Wang, S.; Zhou, Y.; Hu, J.; Li, Q.; He, J. Direct Detection of Local Electric Polarization in the Interfacial Region in Ferroelectric Polymer Nanocomposites. Adv. Mater. 2019, 31, 1807722. [CrossRef]

17. Jespersen, T.S.; Nygard, J. Charge traping in carbon nanotube loops demonstrated by Electrostatic Force Microscopy. Nano Lett. 2005, 5, 1838-1841. [CrossRef]

18. Zheng, C.; Zhang, W.; Zhao, H.; Wang, X.; Sun, Z.; Yang, J. Assessment of nano dielectrics interface charge by electrokinetic sonic amplitude and Atom Force Microscopy. IEEE Trans. Dielectr. Electr. Insul. 2014, 21, 004340. [CrossRef]

19. Ireland, P.M. Contact charge accumulation and separation discharge. J. Electrost. 2009, 67, 462-467. [CrossRef]

20. Walczyk, W.; Hain, N.; SchöNherr, H. Hydrodynamic effects of the tip movement on surface nanobubbles: A combined tapping mode, lift mode and force volume mode AFM study. Soft Matter. 2014, 10, 5945-5954. [CrossRef]

21. Li, Y.; Yasuda, M.; Takada, T. Pulsed electroacoustic method for measurement of charge accumulation in solid dielectrics. IEEE Trans. Dielectr. Electr. Insul. 1994, 94, 300151.

22. Min, D.; Li, Y.; Yan, C.; Xie, D.; Li, S.; Wu, Q.; Xing, Z. Thickness-Dependent DC Electrical Breakdown of Polyimide Modulated by Charge Transport and Molecular Displacement. Polymers 2018, 10, 1012. [CrossRef] [PubMed] 
23. Deschler, J.; Seiler, J.; Kindersberger, J. Detection of charges at the interphase of polymeric nanocomposites. IEEE Trans. Dielectr. Electr. Insul. 2017, 24, 1027-1037. [CrossRef]

24. Franz, J.G. Advances in atomic force microscopy. Rev. Mod. Phys. 2003, 75, 949-983.

25. Pourrahimi, A.M.; Olsson, R.T.; Hedenqvist, M.S. The role of interfaces in polyethylene/metal-oxide nanocomposites for ultrahigh-voltage insulating materials. Adv. Mater. 2017, 30, 1703624. [CrossRef] [PubMed]

26. Zhang, D.; Wang, X.; Song, W.; Sun, Z.; He, L.J.; Han, B.; Lei, Q.Q. Analysis of crystallization property of $\mathrm{LDPE} / \mathrm{Fe}_{3} \mathrm{O}_{4}$ nano-dielectrics based on AFM measurements. J. Mater. Sci. Mater. Electron. 2017, $28,3495$. [CrossRef]

27. Riedel, C.; Alegría, A.; Schwartz, G.A.; Arinero, R.; Colmenero, J.; Sáenz, J.J. On the use of electrostatic force microscopy as a quantitative subsurface characterization technique: A numerical study. Appl. Phys. Lett. 2011, 99, 023101. [CrossRef]

28. Tian, F.; Lei, Q.; Wang, X.; Wang, Y. Effect of deep trapping states on space charge suppression in polyethylene/ZnO nanocomposite. Appl. Phys. Lett. 2011, 99, 142903. [CrossRef]

29. Hoang, A.T.; Pallon, L.; Liu, D.; Serdyuk, Y.V.; Gubanski, S.M.; Gedde, U. Charge Transport in LDPE Nanocomposites Part I Experimental Approach. Polymers 2016, 8, 87. [CrossRef]

30. Mazzanti, G.; Montanari, G.C.; Palmieri, F. Quantities extracted from space-charge measurements as markers for insulation aging. IEEE Trans. Dielectr. Electr. Insul. 2003, 10, 198-203. [CrossRef]

31. Hayase, Y.; Tanaka, Y.; Takada, T.; Murata, Y.; Sekiguchi, Y.; Reddy, C.C. Space charge suppression effect of nano-size fillers added to polymeric materials. J. Phys. Condes. Ser. 2009, 183, 012004. [CrossRef]

(C) 2019 by the authors. Licensee MDPI, Basel, Switzerland. This article is an open access article distributed under the terms and conditions of the Creative Commons Attribution (CC BY) license (http://creativecommons.org/licenses/by/4.0/). 